\title{
ASPEK KENYAMANAN PEJALAN KAKI TERHADAP IKLIM TROPIS DAN AKSESIBILITAS PEJALAN KAKI DI LAPANGAN KOTA SEBAGAI KAWASAN PEDESTRIAN \\ (KAJIAN KAWASAN SIMPANG LIMA SEMARANG )
}

\author{
Esti Yulitriani Tisnaningtyas \\ Universitas Pandanaran \\ Jl. Banjarsari Barat No. 1, Pedalangan, Banyumanik, Semarang \\ email: esty.yulitriani@gmail.com
}

\begin{abstract}
Abstrak
Lapangan atau plaza area berfungsi sebagai tempat aktifitas manusia, sebagai ruang transisi untuk bergerak dari bangunan satu ke bangunan lain atau dari satu tempat ke tempat lain (Cliff, 1992), sebagai tempat interaksi sosial masyarakat kota dan lain-lain. Sebagai negara yang beriklim tropis, Indonesia memiliki dua musim yaitu musim kemarau dengan panas yang cukup terik serta curah hujan yang cukup tinggi di musim hujan. Sebagai kawasan pedestrian harus dapat mengakses seluruh kepentingan kegiatan masyarakat lewat moda berjalan kaki, termasuk yang berkaitan dengan iklim.

Penelitian ini bertujuan untuk mengkaji aspek kenyamanan berjalan kaki terhadap faktor iklim tropis dan aspek aksesibilitas pejalan kaki dalam bergerak di lapangan kota di Indonesia di kawasan pusat kota dalam hal ini Kawasan Simpang Lima Semarang.

Metode penelitian yang digunakan menggunakan metode kualitiatif dengan pendekatan perilaku pejalan kaki. Data diambil dengan pendekatan beahvioral mapping yaitu person centered mapping dan place centerd mapping.

Dari hasil penelitian, diperoleh belum diperoleh kenyamanan berjalan kaki terkait dengan perlindungan terhadap iklim tropis di Lapangan Pancasila maupun di ruang terbuka di sekelilingnya. Aksesibilitas pejalan kaki juga sangat kurang. Hal ini dipengaruhi lalu lintas yang cukup padat dan kencang, adanya PKL di trotoar, pagar dan fasilitas pejalan kaki yang digunakan untuk parkir dan kegiatan lainnya.
\end{abstract}

Keyword : Pedestrian, kenyamanan, tropis

\section{PENDAHULUAN}

Karena kebanyakan kawasan pedestrian direncanakan di luar bangunan, faktor iklim menjadi faktor penting yang harus dipikirkan, karena penanganan terhadap iklim akan membantu menciptakan kenyamanan, selain beberapa faktor lain yang juga perlu dipikirkan secara khusus, seperti faktor keamanan, estetika, kemudahan dan pencapaian. Di sisi lain adanya beberapa perubahan yang terjadi seperti munculnya elemen-elemen tambahan yang merubah kondisi kawasan pedestrian, munculnya pelaku-pelaku kegiatan yang mengganggu aktivitas pejalan kaki, serta terjadinya perubahan fungsi kawasan pedestrian menjadi tempat berjualan pedagang kaki lima.

Perencanaan kawasan pedestrian dalam mengatasi iklim dan cuaca, terlebih terhadap iklim tropis mencakup lebih banyak dari pada sekedar fungsi. Karena selain berbicara tentang teknologi dan dimensi, peranan pedestrian dalam Elemen pergerakan yang berkaitan dengan fungsi perhubungan dalam suatu kota terdiri dari tiga bagian (Hamid Shirvani, 1985), yaitu : transportasi, pedestrian dan parkir.

Tujuan penelitian adalah : kondisi kawasan Simpang Lima sebagai kawasan pedestrain dari aspek akesibilitas pejalan kaki dan kenyamanan terhadap iklim tropis.

Sasaran yang ingin dicapai dari penelitian ini, adalah : Memperoleh masukkan baik secara teoritis maupun faktual mengenai jalur pedestrian, serta elemen-elemen yang dapat menunjang kepentingan dan kebutuhan para pejalan kaki, untuk dikembangkan secara lebih terencana.

Manfaat yang diharapkan dari penelitian ini adalah : Memperluas wawasan tentang moda pergerakkan jalur pedestrian, berdasarkan fakta potensi dan elemen-elemen jalur pedestrian setempat sebagai masukkan bagi perencanaan jalur pedestrian agar mudah diakses oleh 
elemen-elemen perkotaan dan dapat memenuhi kebutuhan serta kepentingan para pejalan kaki secara lebih manusiawi.

\section{METODE PENELITIAN}

Penelitian ini menggunakan Metode Kualitatif dengan Pendekatan Rasionalistik. Metode Kualitatif menuntut adanya sifat holistik, dimana obyek yang diteliti tanpa dilepaskan dari konteksnya (Noeng Muhadjir, 1996). Pendekatan Rasionalistik berlandaskan pada cara berpikir rasional, yang berasal dari pemahaman kemampuan intelektual, yang dibangun atas kemampuan argumentasi secara logika, sehingga lebih ditekankan pada pemaknaan Empiri, dengan cara mengungkapkan fenomena yang terjadi pada suatu lokasi, dengan dukungan Teoritis (Data Sekunder) dan hasil Survei Lapangan (Data Primer). Data diambil dengan pendekatan behavioral mapping yaitu person centered mapping dan place centerd mapping.

\section{HASIL DAN PEMBAHASAN}

\section{Kenyamanan Pejalan Kaki Terhadap Iklim Tropis Dan Aksesibilitas Pejalan Kaki Di Lapangan Kota Sebagai Kawasan Pedestrian}

\section{Iklim Tropis}

"Tropis" diambil dari bahasa Yunani kuno "Tropikos" yang berarti garis balik. Kini pengertian ini berlaku untuk daerah antara kedua garis balik ini, yang meliputi sekitar 40 $\%$ dari luas seluruh permukaan bumi. Garis balik ini menurut ilmu bumi ditentukan garis lintang $23^{\circ} 27^{\prime}$ Utara dan garis lintang $23^{\circ} 27^{\prime}$ Selatan. Posisi garis lintang $23^{\circ} 27^{\prime}$ Utara adalah garis balik Cancer, dimana matahari pada tanggal 22 Juni mencapai posisi tengah tegak lurus. Posisi garis lintang $23^{\circ} 27^{\prime}$ Selatan adalah garis balik Capricorn, dimana matahari pada tanggal 23 Desember mencapai posisi tengah tegak lurus.

\section{Pejalan kaki (Pedestrian)}

Pengertian pedestrian berasal dari kata latin "pedos" yang berarti kaki, sehingga kata pedestrian dapat diartikan sebagai pejalan kaki atau orang yang berjalan kaki, sedangkan jalan yaitu media di atas bumi yang memudahkan manusia dalam tujuan berjalan. Sehingga pedestrian dalam hal ini mempunyai arti pergerakan atau perpindahan orang atau manusia dari satu titik tolak ke tempat lain sebagai tujuan dengan menggunakan moda jalan kaki atau lebih dikenal dengan sebutan jalur pejalan kaki. Titik konsentrasi pejalan kaki disebut sebagai kawasan pedestrian atau nodes. Lapangan kota (town square) merupakan wadah titik konsentrasi pejalan kaki atau kawasan pedestrian juga merupakan wadah pergerakan pejalan kaki menuju ke tempat lain.

Tujuan manusia berjalan kaki.

a. Berjalan kaki untuk perjalanan fungsional, misal ke tempat kerja. Jalur pejalan kaki dirancang untuk tujuan tertentu secara fungsional dengan frekuensi reguler, seperti melakukan perjalanan pulang-pergi ke tempat kerja.

b. Berjalan kaki untuk perjalanan yang tidak terikat waktu, misal berbelanja. Karena perjalanan santai dan kecepatan berjalan rendah, sehingga jarak rata-rata lebih panjang dan sering tanpa disadari ada daya tarik di sekeliling jalur pedestrian yang membuat perjalanan yang ditempuh jadi lebih panjang. Daya tarik tersebut biasanya berupa elemen visual, misalnya window shopping di salah satu sisi sepanjang jalur pedestrian, yang membuat pejalan kaki sering berhenti hanya untuk melihat / memandang barang-barang di depan etalase untk kemudian memutuskan apakah berniat masuk ke dalam toko atau tidak.

c. Berjalan kaki untuk keperluan rekreasi yang dapat dilakukan sewaktu-waktu dengan berjalan santai. Sehingga jalur pedestrian dirancang sedemikian rupa dengan fasilitas pendukung yang bersifat rekreatif seperti : kegiatan berkumpul, duduk-duduk, menikmati pemandangan yang memerlukan ruang terbuka dan dilengkapi elemen pendukung seperti : tempat duduk, lampu penerangan, bak bunga dan lain-lain.

Faktor-faktor yang mempengaruhi panjang/jarak orang untuk berjalan kaki pada jalur pedestrian antara lain:

a. Waktu.

Berjalan kaki pada waktu tertentu akan mempengaruhi jarak perjalanan yang mampu ditempuh. Dari penelitian didapat jarak yang dianggap masih menyenangkan untuk berjalan kaki adalah 455 meter, lebih dari itu orang akan memilih moda angkutan untuk meneruskan perjalanannya.

b. Kenyamanan. 
Kenyamanan orang berjalan kaki dipengaruhi oleh iklim / cuaca dan aktivitasnya, karena iklim dan cuaca yang buruk akan mengurangi keinginan orang untuk berjalan kaki, misal cuaca panas dengan matahari terik atau hujan deras dan banjir. Jarak tempuh yang nyaman untuk berjalan kaki di Indonesia $\pm 400 \mathrm{~m}$.

\section{Lapangan Kota sebagai Kawasan Pedestrian Pada Kawasan Pusat Kota}

Kota harus menyediakan suatu sistemsistem jaringan jalan publik (baik yang tertutup, semi tertutup maupun terbuka), vegetasi, ruang-ruang terbuka, trotoar, ruangruang PKL, titik-titik tempat transportasi publik dan parkir bagi suatu kota. Lapangan atau plaza area berfungsi sebagai tempat aktifitas manusia, sebagai ruang transisi untuk bergerak dari bangunan satu ke bangunan lain atau dari satu tempat ke tempat lain (Cliff, 1992), sebagai tempat interaksi sosial masyarakat kota dll.

Lapangan kota dapat dilihat dalam fungsi atau bentuk. Lapangan bisa mempunyai satu fungsi dominan atau fungsi campuran (Zucker). Lapangan bisa menjadi wadah untuk memamerkan keindahan bangunan-bangunan di sekelilingnya; lapangan berfungsi politis yaitu kenegaraan; sebagai titik pembagi lalu lintas transportasi yang vital di suatu kota; lapangan kota juga berfungsi sebagai kawasan pejalan kaki atau kawasan pedestrian dimana pejalan kaki bisa menikmati berbagai kegiatan di ruang terbuka seperti bermain, berolah raga, menikmati pemandangan di sekitar, berjalanjalan dan sebagainya.

Fungsi lapangan kota bisa tunggal maupun campuran. Terkadang fungsi yang satu bertabrakan dengan fungsi yang lain. Sebagai contoh lapangan kota sebagai titik pembagi transportasi atau titik persilangan transportasi dengan lapangan kota sebagai kawasan pejalan kaki atau kawasan pedestrian.Hal ini memerlukan penyelesaian desain yang baik yang mempertimbangkan fungsi-fungsi tersebut.

Sebagai negara yang beriklim tropis, Indonesia memiliki dua musim yaitu musim kemarau dengan panas yang cukup terik serta curah hujan yang cukup tinggi di musim hujan. Sebagai kawasan pedestrian harus dapat mengakses seluruh kepentingan kegiatan masyarakat lewat moda berjalan kaki, termasuk yang berkaitan dengan iklim.

Dalam perencanaan, lingkungan dianggap menjadi suatu kelompok lokasi lokasi aktivitas dan penghubung-penghubungnya (linkages). Tiap aktivitas punya pilihan site masingmasing atau penghubungnya dengan aktivitas lain. Desain urban bagi kota seharusnya mencari pola-pola lokasi yang optimum, mengingat kepentingan relatif dari setiap aktivitas.

\section{Elemen Pendukung (Street Furniture)}

Untuk menciptakan kenyamanan yang dibutuhkan seseorang dalam melakukan perjalanan dengan berjalan kaki, diperlukan elemen-elemen pendukung jalur pedestrian (street furniture), yaitu :

a. Ground Cover, penutup tanah pada jalur pedestrian dan elemen utama yang menyangkut skala, pola, warna, tekstur, ketinggian dan material, yang dibedakan menjadi Hard Material (paving, beton/concrete), batu bata/brick, batu dan aspal) serta Soft Material (tanah liat/gravel dan rumput/grass). Perencanaan ground cover tergantung dari fungsi dan jenis jalur pedestrian.

b. Peneduh/Shelter, berbentuk linier sebagai koridor atau sitting group yang fungsinya dapat berupa tempat untuk istirahat, berteduh dari panas terik atau hujan, maupun untuk halte pemberhentian jalur angkutan umum.

c. Tanaman/vegetasi, selain sebagai elemen estetis, tanaman pada jalur pedestrian dapt berfungsi sebagai pembatas jalur pedestrian dengan jalur lalu lintas kendaraan atau parkir, barier yang dapat mengurangi deru bising serta asap kendaraan bermotor serta peneduh pada saat hujan dan mengurangi radiasi panas matahari.

\section{Aspek Kenyamanan Pejalan Kaki Terhadap Iklim Tropis}

Beberapa elemen iklim yang mempengaruhi tingkat kenyamanan, adalah sebagai berikut:

a. Temperatur udara, batas kenyamanan di daerah khatulistiwa adalah suhu udara berkisar $22,5^{\circ} \mathrm{C}-29,5^{\circ} \mathrm{C}$.

b. Radiasi matahari, daerah khatulistiwa merupakan daerah yang paling banyak 
menerima radiasi matahari. Panas tertinggi dicapai \pm 2 jam setelah tengah hari pada saat radiasi matahari langsung bergabung dengan udara yang sudah tinggi. Sebanyak $43 \%$ radiasi matahari dipantulkan kembali, $57 \%$ diserap (14\% diserap atmosfir dan $43 \%$ diserap permukaan bumi).

c. Kelembaban udara, kelembaban udara dapat mengalami fluktuasi yang tinggi, terutama sangat tergantung pada temperatur udara. Semakin tinggi temperatur semakin tinggi kemampuan menyerap air. Kenyamanan yang dapat dicapai di daerah khatulistiwa menurut Lippsmeier adalah dengan kelembaban udara berkisar antara $20 \%-50 \%$.

d. Pergerakan udara, adalah gerakan yang terjadi akibat pemanasan lapisan-lapisan udara yang berbeda-beda, dan mempengaruhi tingkat kecepatan angin.

e. Curah Hujan, curah hujan yang tinggi dapat meningkatkan kelembaban udara dan mendinginkan suhu ruangan.

f. Tanaman, selain sebagai fungsi estetika, tanaman berfungsi juga untuk pengendali musim, yaitu sebagai peneduh, barier angin yang masuk bangunan dan barier radiasi panas matahari.

\section{Aksesibilitas Pejalan Kaki (Pedestrian Accessible)}

Akses pejalan kaki kota harus juga memperhatikan tingkat pelayanan fasilitas pejalan kaki pada kawasan pedestrian, yang meliputi :

a. Kecepatan Pejalan Kaki (pedestrian speed), yaitu rata-rata kecepatan berjalan pejalan kaki dalam hitungan meter per menit.

b. Tingkat Arus Pejalan Kaki (pedestrian flow rate), yaitu jumlah pejalan yang melalui suatu titik (adalah pandangan tegak lurus melalui lebar trotoar) tiap menit yang dinyatakan dalam satuan meter per menit.

c. Satuan Lebar (unit width flow), yaitu ratarata arus pejalan per satuan lebar trotoar efektif yang dinyatakan dalam satuan orang per menit per meter.

d. Rombongan/Kelompok Pejalan (platoon), adalah sejumlah pejalan yang berjalan bersama-sama dalam suatu kelompok, biasanya secara tidak sengaja karena pengendali lalu lintas seperti lampu merah dan faktor-faktor lainnya. e. Kepadatan Jalan (pedestrian density), adalah rata-rata jumlah pejalan per satuan ruang, dinyatakan dalam orang per meter persegi.

f. Ruang Pejalan (pedestrian space), adalah rata-rata daerah yang tersedia untuk tiap pejalan pada suatu trotoar yang dinyatakan dalam meter persegi per orang.

\section{Hasil Penelitian}

\section{Kondisi Lokasi Kawasan Simpang Lima}

Kawasan Simpang Lima merupakan kawasan pedestrian, dengan open space berbentuk Lapangan yang dikelilingi sirkulasi lalu lintas yang cukup padat, dengan bangunan komersiil din sekitarnya. Jalan yang menuju ke Simpang Lima yaitru jalan Pahlawan, jalan A Yani, Jl. Ahmad Dahlan, jalan Gajah Mada dan Jalan Pandanaran. Kawasan Simpang Lima merupakan kawasan pusat kota yang berkarakteristik modern dengan hotel dan pusat perbelanjaan modern di sekelilingnya.

Pencapaian menuju ke bangunan-bangunan di Simpang Lima melalui jalan Simpang Lima yaitu jalan yang mengelilingi Lapangan Pancasila. Dari jalan Simpang Lima (jalur cepat) kendaraan memasuki jalur lambat baru kemudian masuk ke kapling masing-masing. Kepadatan lalu lintas di kawasan ini cukup tinggi.

\section{Lapangan}

Lapangan Pancasila merupakan lapangan rumput yang cukup luas dan terbuka dengan perkerasan di sekelilingnya. Luas lapangan Pancasila kurang lebih1,8 hektar, dengan sisi panjang 182,50 meter dan sisi pendek 113,5 meter. Jalur pedestrian yang ada mempunyai perbedaan ketinggian dengan permuk.aan jalan yang mengitari lapangan Pancasila. Tinggi permukaan perkerasan dari permukaan jalan yaitu 70 centimeter. Dinding perkerasan mempunyai kemiringan dengan sudut 80 derajat. Jalu lintasnya yang cukup padat.

\section{Trotoar}

Di kawasan Simpang Lima trotoar yang mengelilingi lapangan Pancasila mempunyai lebar enam meter dengan peninggian 60 centimeter. Trotoar di Simpang Lima merupakan jalur pejalan kaki yang terbuka tidak berpenutup. Trotoar di Simpang Lima 
dapat digunakan sepenuhnya oleh pejalan kaki hanya pada pagi hari hingga sore hari. Sedangkan pada siang hingga malam hari, bahkan ada yang hingga pagi hari, sebagian digunakan pedagang kaki lima untuk berjualan. Trotoar di Simpang Lima ini merupakan jalur yang terpisah dari bangunanbangunan yang mengelilingi lapangan Pancasila, dibatasi oleh pagar dan tempat parkir. Trotoar lainnya yang cukup menarik adalah piasa kecil.

Trotoar lainnya adalah trotoar di depan bangunan yang mengelilingi Lapangan Pancasila. Namun diantara bangunan dengan trotoar terdapat parkir kendaraan bermotor dan pagar. Pejalan kaki yang akan menuju ke bangunan dari jalan raya harus melalui pintu pembatas parkir dengan trotoar.

Jalur pejalan kaki yang berbentuk trotoar saat ini dialih fungsikan untuk berjualan pedagang kaki lima dan berhimpitan dengan tempat parkir liar, pejalan kaki bila hendak melintasi harus berjalan di sela-sela meja PKL atau lebih memilih berjalan di sisi jalan raya. Sedangkan di sisi luar trotoar, dimanfaatkan sebagai tempat parkir kendaraan roda empat maupun roda dua.

\section{Perilaku Pejalan Kaki}

a. Melintas Lapangan Pancasila.

Dari pergerakan pejalan kaki diperoleh bahwa pergerakan kaki pada siang hari lebih banyak berapa di ruang antar bangunan terdekat. Sedikit sekali pejalan kaki yang memanfaatkan lapangan untuk bergerak dari satu bangunan menuju ke bangunan lain di seberang lapangan. Pada sore hari ditemukan beberapa pejalan kaki yang memanfaatkan lapangan Pancasila sebagai ruang untuk bergerak dari satu bangunan menuju ke bangunan lain di seberang lapangan walapun harus susah payah menyeberangi lalu lintas yang padat dan naik ke trotor di tepi lapangan Pancasila yang cukup tinggi yaitu $60 \mathrm{~cm}$.

b. Melintas pinggir Lapangan (didepan

Jalur pejalan kaki yang berbentuk trotoar saat ini dialih fungsikan untuk berjualan pedagang kaki lima dan berhimpitan dengan tempat parkir liar, sehingga pejalan kaki lebih memilih berjalan di sisi jalan raya. Sedangkan di sisi luar trotoar, dimanfaatkan sebagai tempat parkir kendaraan roda empat maupun roda dua. Dari pergerakan pejalan kaki diperoleh bahwa pergerakan kaki pada siang hari lebih banyak dari sisi samping bangunan satu ke sisi samping bangunan lain.. Sedikit sekali pejalan kaki yang memanfaatkan ruang terbuka depan bangunan atau di badan jalan Simpang Lima untuk bergerak dari satu tempat ke tempat lain. Pada sore hari juga pergerakan pejalan kaki sama.

Ada juga pejalan kaki yang melintasi trotoar yang ada PKL tersebut untuk bergerak menuju ke tempat lain, namun dengan perjuangan karena sisa lebar trotoar yang ada tinggal 1 meter, bahkan di beberapa tempat terhalang meja milik PKL.

c. Menuju ke Lapangan Pancasila dan sebaliknya

Pejalan kaki bergerak menuju ke Simpang Lima lebih banyak pada sore hingga malam hari dari segala arah sisi lapangan Pancasila walaupun terpaksa naik ke trotoar dengan ke tinggian $60 \mathrm{~cm}$ dan ada anak tangga di depan hotel Citraland, depan ujung jalan A Yani, depan ujung jalan Pahlawan, depan ujung Jalan Pandanaran.

d. Pejalan kaki berkegiatan di tempat

Pejalan kaki memanfaatkan lapangan Pancasila untuk kegiatan bersantai, berolah raga, berjalan-jalan, bermain pada sore hingga malam hari, atau pada pagi hari saat libur . Pada siang hari tidak terlihat ada kegiatan.

Pejalan kaki memanfaatkan ruang atau trrotoar di depan bangunan untuk menuju ke pedagang makanan yang diinginkan dan duduk-duduk menikmati makanan . Kegiatan ini berlangsung dari sore hingga malam hari.

\section{Kontrol Terhadap Iklim}

Secara khusus jalur pedestrian di kawasan Simpang Lima Semarang di sepanjang Jalan Simpang Lima kurang menciptakan respon terhadap pengaruh iklim, terutama iklim tropis di kota Semarang. Elemen-elemen lain yang secara tidak langsung menangkal iklim dan cuaca, adalah:

\section{a. Pembayangan}

- Sisi Barat

Ketinggian bangunan Gajah Mada Plaza dengan ketinggian banggunan tiga lantai atau sekitar 12 meter memberikan keterlindungan pada trotoar di sisi Barat pada pagi sampai siang hari, karena ketinggian bangunan menciptakan 
pembayangan matahari pada trotoar Jalan Simpang Lima di depan pertokoan Gajah Mada Plasa sisi Barat Lapangan Pancasila. Namun Bangunan Pertokoan Gajah Mada Plasa tidak bisa memberikan perlindungan pada Lapangan Pancasila.

- Sisi Timur Lapangan Pancasila

Ketinggian bangunan Pertokoan Simpang Lima dengan ketinggian banggunan dua lantai atau sekitar 8 meter memberikan keterlindungan pada tempat parkir pertokoan Simpang Lima pada siang sampai sore hari, pembayangan karena ketinggian bangunan tidak mencapai jalur pedestrian didepan pertokoan dan Lapangan Pancasila.

Ketinggian bangunan Simpang Lima Plasa dengan ketinggian banggunan 7 lantai atau sekitar 32 meter memberikan pembayangan pada tempat parkir Simpang Lima Plasa, jalur pedestrian didepan pertokoan dan Lapangan Pancasila. pada siang sampai sore hari. Di depan bangunan Simpang Lima ada beberapa pohon yang dapat berfungsi sebagai peneduh.

- Sisi selatan Lapangan Pancasila Disisi selatan ada bangunan House dengan ketinggian bangunan 5 lantai, Kantor Telkom dengan ketinggian 2 lantai, SMK Negeri dengan ketinggian bangunan 1-2 lantai bangunan ini mengapit jalan Pahlawan. Bangunan House ada disisi timur Jalan Pahlawan, sedangkan bangunan ada di sisi barat Jalan Pahlawan.

Untuk Ruang terbuka Lapangan Pancasila dan trotoar di sisi selatan Lapangan Pancasila, Bangunanbangunan yang ada tidak memberikan perlindungan terhadap Ruang publik tersebut. Bangunan-bangunan tersebut memberikan manfaat dan perlindungan di trotoar jalan pahlawan.

- Sisi Utara Lapangan Pancasila

Di sisi utara Lapangan Pancasila terdapat bangunan Hotel Citraland, bnetuk bangunan berundak-undak dengan ketinggian bangunan 5 lantai. Bangunan ini tidak memberikan perlindungan terhadap ruang Publik
Lapangan Pancasila dan trotoar di sekelilingnya.

Deretan pohon Glodogan pecut palem yang ditanam ditepi trotoar Lapangan Pancasila diharapkan untuk menciptakan pemandangan yang indah dan udara yang sehat, bebas polusi; namun Mengontrol suhu diperoleh melaui pembayangan dari sisi barat dan timur namun kurang berfungsi secara maksimal karena bentuk tajuknya tidak bisa berfungsi sebagai peneduh area di bawahnya. Beberapa pohon peneduh yang ada cukup memberikan perlindungan bagi pengunjung atau pejalan kaki yang duduk-duduk di tempat duduk yang disediakan di bawah pohon.

\section{b. Hard material}

- Paving: Lantai yang menutupi permukaan trotoar yang mengelilingi lapangan Pancasila dengan ketinggian $60 \mathrm{~cm}$ dari badan jalan Simpang Lima dan didisain agar pengguna Lapangan Pancasila tidak dapat menuju ke lapangan Pancasila dari segala arah mengingat lalu lintas yang cukup padat dan kencang. Untuk pejalan kaki yang menikmati berkeliling Lapangan melalui trotoar ini. Di tengah lapangan tidak ada trotoar yang melintas, semua berupa lapangan rumput, sehingga pejalan kaki yang melintas di tengah lapangan terpaksa menginjak rumput yang ada.

- Badan Jalan dan parkir

Di luar lapangan, berupa jalan aspal dan tempat parkir yang terbuat dari paving blok.

c. Soft material

- Tanaman/Vegetasi: Berupa pohon glodogan pecut mengelilingi lapangan, pohon peneduh dan tanaman hias di beberapa tempat di pinggir Lapangan Pancasila, serta pot bunga yang diletakan pada trotoar pingir lapangan. Tengah lapangan Pancasila berupa tanaman rumput yang cukup luas.

d. Elemen pendukung

- Shelter ada di tempat pemberhentian bis dan PKL, di Lapangan Pancasila tidak ada shleter yang dapat melindungi dari panas selain pohon peneduh 


\section{Analisa}

1. Aksesibilitas Pejalan Kaki (Pedestrian Accesible)

Hasil penelitian ini memberikan hasil, bahwa kawasan pedestrian di Simpang Lima tidak mudah diakses. Dimana akan menimbulkan aspek yang tidak saja secara fisik, tetapi juga secara psikologis dirasakan oleh para pejalan kaki sebagai suatu peningkatan kualitas terhadap kemudahan dalam berjalan kaki. Dari hasil pengamatan pada perilaku pejalan kaki, pejalan kaki mengalami hambatan dalam bergerak karena adanya trotoar depan bangunan diperuntukan untuk PKL dengan sistem pujasera yaitu didepan Simpang Lima Plasa, depan Pertokoan Simpang Lima depan Robinson, depan kantor Telkom dan SMK 12, depan Pertokoan Gajah Mada Plasa. Lebar trotoar tersisa 0,5 sampai 5 meter. Pejalan kaki mempunyai ruang teritori, begitu ruang tidak cukup leluasa untuk bergerak maka akan mencari alternatif lain. Untuk pengunjung Simpang Lima yang memang hendak berwisata kuliner keberadaan PKL yang ada menjadi daya tarik untuk berkunjung dan beraktifitas. Tetapi pejalan kaki dengan tujuan untuk melintas atau bergerak ke tempat lain, ini merupakan hambatan berupa kesesakan atau crowded. (Utterman, 1984).

a. Adanya taman pemisah jalur lambat dengan jalur cepat. Badan jalan depan trotoar di depan bangunan ditempati parkir kendaraan. Pejalan kaki dari trotoar menuju ke lapangan Pancasila masih harus melewati jalur lambat taman dengan atau sebaliknya terhambat adanya taman dan parkir depan bangunan.

b. Adanya parkir liar becak, kendaraan pengunjung dan taksi. Bila ada halangan maka pejalan kaki memilih tempat lain untuk bergerak dengan mudah. (Cliff, 1992)

c. Lalu lintas yang padat dan kencang. Pejalan kaki harus berkali-kali berhenti menunggu kendaraan lewat. Selain hambatan membuat orang enggan menuju ke Simpang Lima, aspek keamanan pejalan kaki terhadap lalu lintas kendaraan menjadi unsur yang mempengaruhi keinginan orang untuk menuju ke Simpang Lima. (Rubeinbstein, 1992). d. Ruang kota depan bangunan digunakan untuk parkir.

e. Pagar bangunan

Pagar bangunan menghalangi kebebasan pejalan kaki dalam bergerak. Masih terkotak-kotak ruang publik yang ada, batas kapling dengan menggunakan pagar, Tidak ada kesatuan ruang kota yang memberikan kebebasan pejalan kaki bergerak. Ini terlihat lebih banyak pejalan kaki yang bergerak dari parkir ke dalam bangunan daripada dari bangunan ke lapangan. Hambatan mempengaruhi membatasai tujuan orang berjalan kaki (Utterman, 1984)

f. Digunakannya trotoar untuk parkir taksi dan lain-lain.

g. Desain trotoar di Lapangan Pancasila yang cukup tinggi, pejalan kaki tidak mudah melewatinya karena harus melompat. Di satu sisi memang dirancang untuk mengarahkan pejalan kaki agar tidak menyeberang di sembarang tempat. Karena Simpang Lima merupakan titik pertemuan lalu lintas yang cukup padat. Adanya hambatan membuat pejalan kaki menentukan pilihan untuk tidak ke Lapangan Pancasila. Tetapi ada juga pejalan kaki yang memaksakan diri untuk melompat. Tetapi hal ini menunjukkan bahwa pejalan kaki akan mencari jalur yang terpendek untuk bergerak (Sirvani, 1985).

h. Desain Lapangan Pancasila dan sekelilingnya masih diprioritaskan sebagai titik pembagi atau pertemuan sirkulasi transportasi di pusat kota. Desain yang ada membuat aksesibilitas pejalan kaki menjadi rendah. Dan membuat Lapangan Pancasila sebagai kawasan pedestrian tidak menarik pejalan kaki untuk beraktifitas pada saat lalu lintas padat. Hal ini terlihat pada saat lalu lintas ke Simpang Lima ditutup , pejalan kaki dengan leluasa bergerak dan menikmati ruang terbuka yang ada, bahkan ada yang duduk-duduk di tengah jalan walaupun cuaca mulai panas.

2. Kenyamanan Pejalan Kaki Terhadap Iklim Tropis (Pedestrian Comfortibility For Tropical Clime).

Kenyamanan terhadap kondisi iklim tropis antara lain:

a. Tingkat kenyamanan terhadap panas kurang. Kurangnya perlindungan terhadap panas pada siang hari bagi pejalan kaki yang melintasi maupun yang beraktifitas di 
lapangan Pancasila baik dari bangunan maupun vegetasi yang ada berakibat pada kurangnya kenyamanan pejalan kaki beraktifitas, hal ini ditunjukkan dengan sedikitnya pejalan kaki yang melintasi lapangan Pancasila pada siang hari dibandingkan dengan sore hari.

b. Kecepatan angin dirasakan cukup kencang bagi pengunjung Lapangan Pancasila. Lapangan Pancasila yang cukup luas mempengaruhi gerakan udara dan kecepatan angin. Gerakan udara dan kecepatan angin cukup tinggi, bagi pejalan kaki yang tidak terbiasa bila berlama-lama di Lapangan Pancasila akan terpengaruh kenyamanan fisiknya. Pejalan kaki merasakan kecepatan angin cukup kencang. Vegetasi atau bangunan yang ada di kawasan Simpang Lima kurang menghalangi kecepatan angin yang ada.

c. Posisi pedestrian yang berada diantara bangunan disepanjang jalan yang menuju ke kawasan Simpang Lima membentuk semacam lorong terbuka. Hal ini sangat menguntungkan, karena jalur pedestrian sepanjang itu akan dilewati angin dengan pergerakan udara yang cepat dan kecepatan angin yang tinggi. Sehingga udara di sekitar pedestrian menjadi sejuk. Kondisi ini masih dibantu dengan deretan vegetasi dan tanaman di sisi jalan yang mempengaruhi pergerakan angin.

d. Perlindungan terhadap hujan, sangat kurang. Perlindungan terhadap hujan masih sangat kurang, terutama di Lapangan Pancasila. Tidak ada shelter di trotoar Lapangan Pancasila, sehingga kalau terjadi hujan maka tidak ada perlindungan bagi pejalan kaki. Perlindungan ini hanya diperoleh di trotoar di depan bangunan di sekitar Lapangan Pancasila, karena ada bangunan permanen untuk PKL pujasera sebagai alternatif untuk berlindung pada saat hujan.

\section{SIMPULAN DAN SARAN}

\section{Simpulan}

Secara umum Indonesia termasuk dalam iklim tropis basah, dimana presifikasi dan kelembaban tinggi, dengan temperatur yang hampir selalu tinggi, angin relatif sedikit, perubahan panas kecil karena tingginya kelembaban. Perubahan musim kecil dan curah hujan tinggi. Radiasi matahari langsung relatif sedang tinggi karena pantulan radiasi oleh awan tergolong sedang dan refleksi radiasi matahari langsung pada tanah sedikit. Dengan kondisi iklim yang demikian, jalur pedestrian yang dibangun di daerah perkotaan harus direncanakan untuk dapat merespon terhadap gangguan iklim tropis tersebut.

Moda berjalan kaki yang menyenangkan, aman dan nyaman akan menarik orang untuk semakin menggunakan moda jalan kaki ini sesuai dengan tujuan perjalanan yang dipilihnya, sehingga kecenderungan berjalan kaki akan lebih besar, terlebih lagi bila berjalan dirasa lebih mudah, lebih cepat atau lebih murah dari pada mengendarai kendaraan bermotor.

Dengan demikian jalur pejalan kaki (pedestrian) harus dirancang sedemikian rupa, dan memenuhi aspek-aspek antara lain sebagai berikut :

1. Mudah/leluasa bergerak dengan cukup terlindungi baik dari iklim, cuaca maupun bahaya kendaraan bermotor.

2. Mudah dilakukan ke segala arah tanpa kesulitan, hambatan dan gangguan yang disebabkan ruang yang sempit dan permukaan lantai yang naik-turun dan panjang.

\section{Saran}

Kiranya kenyataan menunjukkan bahwa di beberapa pusat kota, kawasan jalur pedestrian yang telah direncanakan dan dibangun sedemikian rupa kurang mendapat tanggapan yang bagus bagi para pejalan kaki. Para pejalan kaki hanya memanfaatkan jalur pedestrian di sekitar tempat belanja atau mall. Ada beberapa hal yang harus dipikirkan/direncanakan dengan lebih matang untuk membuat jalur pedestrian terutama di perkotaan agar dapat dimanfaatkan secara maksimal, yaitu :

1. Faktor kenyamanan terhadap iklim tropis:

Lapangan Pancasila sebagai lapangan rumput tetap dipertahankan, tetapi perlu penambahan vegetasi yang berfungsi sebagai peneduh, penghalang angin dan memberikan oksigen yang cukup. Perlunya unsur peneduh untuk melindungi badan jalan agar aspal tidak menjadi panas. Hal ini sangat dirasakan apabila orang melalui jalur pedestrian pada waktu siang hari. 
Iklim tropis di Indonesia mengakibatkan radiasi dan terik panas matahari siang hari sangat menyengat. Tidak adanya unsur peneduh dari panas matahari yang membuat orang malas untuk berjalan di siang hari serta upaya dalam mencegah polusi udara di kota besar yang meningkat melebihi batas ambang pencemaran yang disyaratkan yang membuat orang malas untuk berjalan kaki, karena asap kendaraan bermotor sangat pedih di mata dan mengganggu pernafasan.

2. Faktor Aksesiblitas

Halangan fisik berupa lalu lintas yang padat. Didisan dengan under pass atau jembatan penyeberangan, hingga memudahkan pejalan kaki menyeberang ke lapangan Pancasila. Namun bila berbentuk underpass maka harus didisain lebar, diberi aktifitas retail agar tidak menakutkan. Drainase diatur dengan baik bisa dengan sistem mekanik.

\section{DAFTAR PUSTAKA}

Eko Budihardjo, Djoko Sujarto, "Kota Yang Berkelanjutan", Direktorat Jenderal Pendidikan Tinggi, Departemen Pendidikan Dan Kebudayaan, Jakarta, 1998.

Hamid Shirvani, "The Urban Design Process", Van Norstand Reinhold Co, New York, 1985.

Harvey M. Rubenstein, "Pedestrian Malls, Streetscapes and Urban Spaces", John Wiley \& Sons Inc., New York, 1992.

Ken Yeang, "The Tropical Verandah City", Asia Publications, Percetakan Sinar Grafiks Sdn. Bhd., Kuala Lumpur, 1986.

Michelson, William, 1975. "Behavioral Research Methods in Environmental Design ", Dowden, Hutchingson \& Ross. Inc,

Paul D. Spreiregen, "Urban Design : The Architecture Of Town And Cities", Mc.Graw Hill Book Company, New York, 1965.

Rapopport, Amos, 1997. "Human Aspects of Urban Form, Towards a Man Environment Approach to Urban Form and Design", Perhamon Press, First Edition,

$\begin{array}{ccc}\text { Setiawan, Hariadi } & \text { B, 1995. "Arsitektur } \\ \text { Lingkungan } & \text { dan } & \text { Perilaku”, } \\ \text { DirektoratJendral } & \text { Pendidikan Tinggi }\end{array}$

Departemen Pendidikan dan Kebudayaan, Jakarta

Unterman, Richarc, 1984,"The Pendestrian and The Bysiclist." 